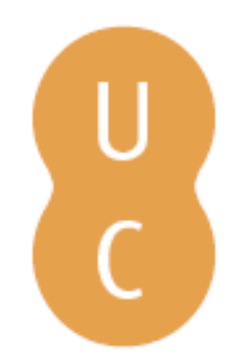

\title{
nommalina
}

\section{A importância da modernização cadastral na gestão territorial urbana no Município de Cascavel (Estado do Paraná - Brasil)}

Autor(es): $\quad$ Pelegrina, Marcos Aurélio; Canal, Máicon Altir; Julião, Rui Pedro

Publicado por: Imprensa da Universidade de Coimbra

URL

persistente: URI:http://hdl.handle.net/10316.2/37078

DOI: $\quad$ DOI:http://dx.doi.org/10.14195/978-989-26-0983-6_25

Accessed : $\quad$ 26-Apr-2023 15:24:05

A navegação consulta e descarregamento dos títulos inseridos nas Bibliotecas Digitais UC Digitalis, UC Pombalina e UC Impactum, pressupõem a aceitação plena e sem reservas dos Termos e Condições de Uso destas Bibliotecas Digitais, disponíveis em https://digitalis.uc.pt/pt-pt/termos.

Conforme exposto nos referidos Termos e Condições de Uso, o descarregamento de títulos de acesso restrito requer uma licença válida de autorização devendo o utilizador aceder ao(s) documento(s) a partir de um endereço de IP da instituição detentora da supramencionada licença.

Ao utilizador é apenas permitido o descarregamento para uso pessoal, pelo que o emprego do(s) título(s) descarregado(s) para outro fim, designadamente comercial, carece de autorização do respetivo autor ou editor da obra.

Na medida em que todas as obras da UC Digitalis se encontram protegidas pelo Código do Direito de Autor e Direitos Conexos e demais legislação aplicável, toda a cópia, parcial ou total, deste documento, nos casos em que é legalmente admitida, deverá conter ou fazer-se acompanhar por este aviso.

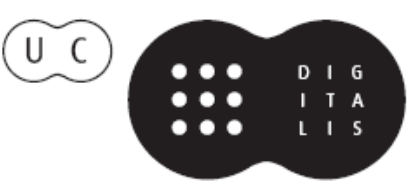




\section{$\forall$ \\ TAS DAS I JORNADAS LUSÓFONAS DE CIÊNCIAS E TECNOLOGIAS DE INFORMAÇÃO GEOGRÁFICA}

Editores

José Gomes dos Santos

Cidália Fonte

Rui Ferreira de Figueiredo

Alberto Cardoso

Gil Gonçalves

José Paulo Almeida

Sara Baptista 


\begin{abstract}
ARTIGO 25
A IMPORTÂnCIA DA MODERNIZAÇão CADASTRAL NA GESTÃo TERRITORIAL URBANA NO MUNICÍPIO DE CASCAVEL - ESTAdo do PARANÁ - BRASil PELEGRINA, Marcos Aurélio'; CANAL, Máicon Altir ${ }^{2}$; JULIÃO, Rui Pedro 3

\footnotetext{
1 Departamento de Geografia da Universidade Estadual do Centro-Oeste do Paraná (Brasil); Bolsista CAPES Processo n. BEX-9757/13-9; Tel: +55 (42) 3629-8100 ; email: marcospelegrina@gmail.com 2 Prefeitura Municipal de Cascavel - Estado do Paraná - Brasil; Tel: +55 4533212382; email: maiconc@cascavel.pr.gov.br

3 e-GEO-FCSH/UNL (Portugal); Morada: Avenida de Berna, 26-C / 1069-061 Lisboa; Tel: +351217908300; email: rpj@fcsh.unl.pt
}

\title{
RESUMO
}

Nos últimos anos o município de Cascavel, Estado do Paraná, Brasil, desenvolveu políticas públicas com vista à implementação do cadastro multifinalitário. Tendo também desenvolvido um Sistema de Informações territoriais via WEB, para a disponibilização de dados e informações cadastrais. O objetivo deste trabalho é apresentar os resultados da implementação da consulta de viabilidade via WEB, presente na modernização cadastral no município de Cascavel.

\section{PALAVRAS-ChAVE}

Geotecnologias, Cadastro multifinalitário, Sistema de informações territoriais. 


\title{
PROPERTY CADASTRAL MODERNIZATION IN THE \\ URBAN LAND MANAGEMENT OF CASCAVEL
}

MUNICIPALITY (PARANÁ, BRAZIL)

\begin{abstract}
In the last years the city of Cascavel in Paraná Brazil, developed policies to implement the multipurpose cadastre. Having also developed a land information system for WEB, and registration information. The objective of this paper is to present the results of implementing the consult planning WEB present in cadastral updating in Cascavel.
\end{abstract}

\section{KEYWORDS}

Geotechnology, Multipurpose cadastre, Land information system.

\section{INTRODUÇÃO}

Anteriormente, a disponibilização da informação cadastral via WEB na Prefeitura Municipal de Cascavel, Estado do Paraná, Brasil. O sistema responsável pela gestão cadastral urbana do município era informatizado, qual permitia o cadastramento, atualização, e armazenamento dos dados de cada unidade cadastral de forma alfanumérica, assim como os dados para cobrança do IPTU (Imposto Predial Territorial Urbano). Nenhum tipo de sistema com suporte para base de dados geográficos era utilizado. Também verificava-se uma carência de profissionais especializados em geoprocessamento e de cadastro multifinalitário no corpo técnico da prefeitura. Esses fatos somados ao não emprego de um SIT (Sistema de Informações Territoriais), ocasionavam incoerência em alguns dados e inúmeras falhas na gestão territorial.

Pela falta de mão de obra qualificada e a escassez de recursos, foram contratados serviços técnicos especializados para a modernização do cadastro. As principais ações desenvolvidas foram: a) Conversão do sistema Geodésico de referência de SAD69 para SIRGAS2000; b) Preparação da base cartográfica para um SIT via WEB; c) Geocodificação dos imóveis; d) Migração das bases de dados disponíveis numa única base cadastral consolidada; e) Consultoria para auxílio na elaboração da planta de valores do município; f) Estudo e implementação do modelo de dados 
para o cadastro de logradouros; g) Desenvolvimento de sistemas computacionais para migração de dados existente para o novo modelo que deveria ser desenvolvido; h) Curso de capacitação em Cadastro e geotecnologias aplicadas a gestão territorial para os técnicos da prefeitura; i) Implantação de SIT via WEB de consulta de viabilidade de edificação, parcelamento do solo e estabelecimento; j) Implantação de sistemas de dados geoespaciais; k) Desenvolvimento de interfaces de utilização do cadastro técnico municipal.

A modernização cadastral executada teve como objetivo o desenvolvimento de um SIT via WEB, possibilitando uma base de dados geográficos sobre o território urbano, a fim de, auxiliar a administração municipal no avanço da qualidade na prestação de serviços e na promoção da justiça tributária.

O objetivo deste trabalho é apresentar os resultados da implementação da consulta de viabilidade via WEB, presente na modernização cadastral no município de Cascavel.

\section{IMPLANTAÇÃo DE CONSULTAS VIABILIDAdE VIA WEB}

O Cadastro Multifinalitário além de melhorar gestão pública e beneficiar os cidadãos independentemente do âmbito de sua competência, também disponibiliza para os usuários da informação cadastral os seguintes produtos: a) base cartográfica cadastral digital; b) informações cadastrais referentes as parcelas territoriais; c) informações da valorização imobiliária de cada parcela; d) informações sobre o planeamento urbano relacionados as parcelas territoriais; e)fornece o zoneamento urbano de cada parcela; f) fornece informações relativas a quaisquer regulamentos governamentais locais; g) fornece informações relativas às parcelas , estradas e ambiente, dentro e em torno de cada parcela; (MAJID, 2000).

Uma das principais funções do cadastro multifinalitário é publicitar os direitos e restrições sobre determinada parcela territorial. No ambiente urbano os direitos e restrições estão presentes na legislação urbana referente ao uso e ocupação do território que é dividida entre o código de obras e edificações, que visa normatizar toda e qualquer construção, 
reforma e ampliação de edifícios efetuada a qualquer título no território do município. A lei de zoneamento e uso do solo, que visa disciplinar a vocação e a finalidade de cada zona ou área do território urbano, objetivando o desenvolvimento harmonioso da comunidade, assegurando a sua qualidade de vida.

No município de Cascavel a modernização cadastral permitiu a publicação de um aplicativo interativo de consulta de viabilidade através do Geoportal Cascavel, link: ( http://geoportal.cascavel.pr.gov.br:10080/ geo-view/faces/sistema/geo.xhtml). O sistema possibilita ao usuário solicitar informações sobre as permissões de uso de qualquer parcela na área urbana do município por Tipo de Consulta: Edificação, Parcelamento do Solo ou Estabelecimento.

\section{RESULTADOS}

O número total de visitantes na página foi de 106.436, esses acessos referem-se ao período de 02/07/2013 (data do lançamento da consulta de viabilidade) à 30/04/2014 data fechamento da pesquisa, (Figura 1).

Neste período o numero total de consultas de viabilidade foi de 58.532 , correspondendo a $54,99 \%$ do número total de consultas no SIT via WEB. Sendo: Edificação: 36.437 consultas; Parcelamento: 3.723 consultas; Estabelecimento: 18.372 consultas. O número de atendimento no balcão da SEPLAN (Secretaria de Planejamento e Urbanismo) no mesmo período foi de 17.448. No período anterior de julho de 2012 à Abril de 2013 o número foi de 34.098. Ou seja, uma redução no atendimento balcão de $51 \%$.

Anteriormente à disponibilização da consulta via WEB, alguns técnicos municipais responsáveis pelo planeamento urbano dedicavam boa parte do seu tempo ao atendimento ao público, devido à grande procura de informações cadastrais. Após o lançamento da consulta de viabilidade, esses servidores voltaram para suas atividades normais, (LEITE,2013). 


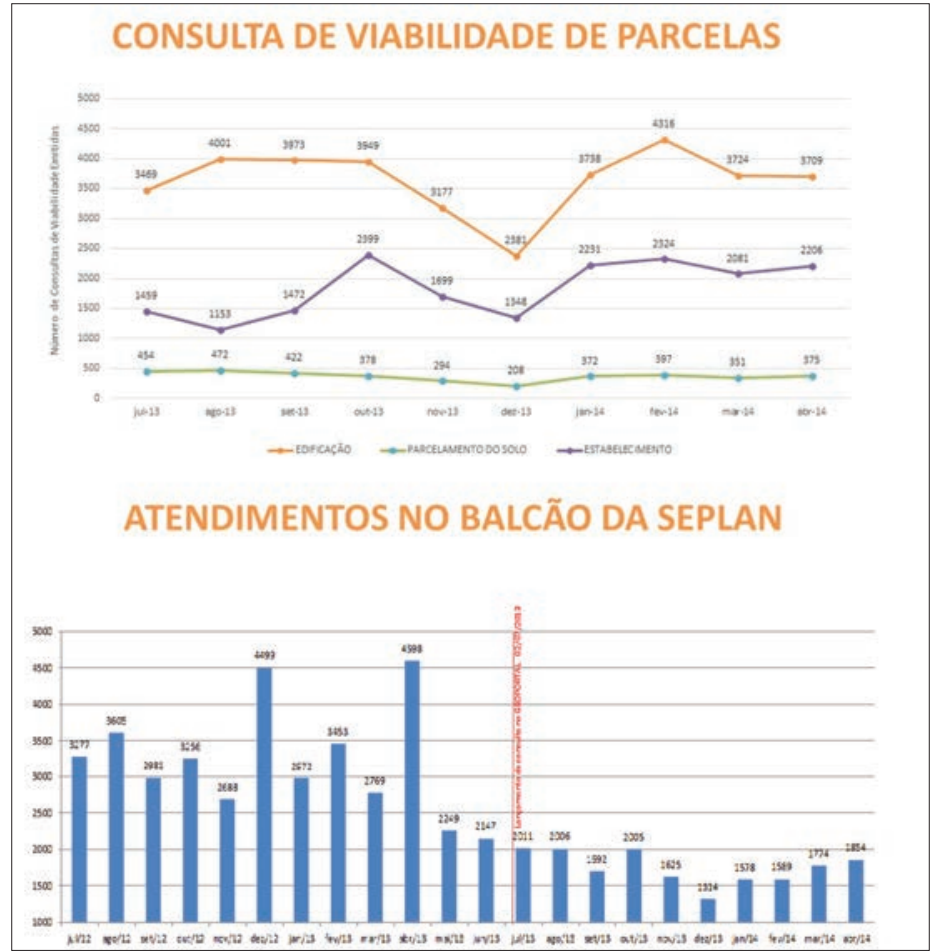

Figura 1 - Números de Consultas de Viabilidade de Parcelas e Número de Atendimentos de Usuários.

Fonte: Prefeitura Municipal de Cascavel,2014.Organizado pelos Autores

\section{CONSIDERAÇÕeS FINAIS E RECOMENDAÇÕeS}

A modernização cadastral e o SIT via WEB (Geoportal Cascavel), publicando informações cadastrais territoriais com dados com a devida qualidade posicional (garantia da precisão e exatidão cartográfica), temática (garantia da qualidade das informações cadastrais), temporal (atualização continua) e facilidade de acesso. Incentivou uma migração de usuários dessas informações (engenheiros, arquitetos, agentes imobiliários e tantos outros) do balcão da SEPLAN para a Internet. Também houve um aumento significativo no número total de consultas.

O aplicativo que disponibiliza informações cadastrais via WEB denominado de Geoportal, atualmente, é utilizado para diferentes fins, desde empresas do setor imobiliário ao poder judiciário até cursos de arquitetura e urbanismo que se valem do aplicativo para atividades académicas 
de Ensino e Pesquisa. É evidente que a implementação do cadastro multifinalitário via WEB, trouxe grandes vantagens para toda sociedade, como segurança jurídica nas transações imobiliárias, maior eficiência no planeamento e na gestão territorial, planeamento e gestão ambiental, no sistema viário, na regularização fundiária, entre outros. Apesar do número significativo de acessos, percebe-se que os usuários ainda são os técnicos e os agentes imobiliários. A disponibilização da consulta de viabilidade via WEB, pautada nas discussões referentes ao Cadastro Multifinalitário, surge como uma tentativa de constituir-se enquanto ferramenta de acesso à informação acerca dos diferentes processos e agentes vinculados à produção do espaço urbano no município. Toda esta dinâmica de produção do espaço urbano em Cascavel traz importantes problemáticas no que diz respeito ao planeamento e gestão territorial. Para que os instrumentos se materializem numa cidade melhor, mecanismos efetivos, que apoiam a fiscalização como a consulta de viabilidade, devem ser criados permitindo que os diferentes segmentos da sociedade civil se apropriem e efetivem a sua participação na produção do espaço urbano e na gestão da cidade.

Recomenda-se, no entanto que, novos estudos para aprofundamento da pesquisa em relação disponibilização das informações cadastrais e seus impactos na produção e na gestão do espaço urbano.

\section{BIBLIOGRAFIA}

FIG - Federação Internacional dos Geômetras, PCGIAP-WorkingGroup3 "Cadastre" FIG-Commission 7 "Cadastre and Land Management". Modelo Cadastral 2003. Disponível na Internet via WWW. URL: http://www.cadastraltemplate. org/, acessado em 08.10.2006.

JULIÃO, R. P. (2001) - Tecnologias de informação geográfica e ciência regional contributos metodológicos para a definição de modelos de apoio à decisão em desenvolvimento regional. Universidade Nova de Lisboa. Lisboa.

LEITE, T.L. (2013) - Avaliação da Reestruturação Cadastral e Implantação de Geotecnologias no Cadastro Técnico Municipal do Município de CascavelPR. Universidade Estadual do Oeste do Paraná. Cascavel-PR.

MAJID, S. A. (2000) - A Multi-Purpose Cadastre Prototype on the Web. A thesis submitted in fulfillment of the requirements for the degree of Master of Geomatics Science. University of Melbourne. Melbourne. 
Série Documentos

Imprensa da Universidade de Coimbra

Coimbra University Press

2015

- U M

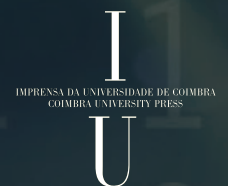

